\title{
Rancangan dan Optimasi Listrik Penerangan Jalan Menggunakan Tenaga Cengkirik
}

\author{
${ }^{(1)}$ Gusti Rusydi Furqon Syahrillah, ${ }^{(2)}$ Sobar Ihsan, ${ }^{(3)}$ Akhmad Maulana \\ (1)(2)(3)Teknik Mesin, Fakultas Teknik, Universitas Islam Kalimantan MAB \\ Jl. Adhiyaksa No. 2 Kayu Tangi, Banjarmasin \\ Email :rani_rusdi@yahoo.com,sobar.uniska@gmail.com,maulana.lana.akhmad@gmail.com
}

\begin{abstract}
Abstrak
Salah saru pembangkit tenaga listrik yang dikembangkan ini adalah dengan berinovasi melalui bentuk dan jenis baling-baling. Pembangkit listrik tenaga angin ini menggunakan baling-baling tradisional yang di namakan dengan cengkirik Pada dasarnya, turbin angin dibuat berbentuk cengkirik ini di rancang untuk menangkap energi dari angin dengan kecepatan rendah yang selanjutnya diteruskan ke rotor yang berputar karena dorongan dari angin akibat dari kecepatan kendarraan. Penelitian ini dilakukan menggunakan metode pendekatan secara teoritis dan eksperimental. terhadap turbin angin. Metode penelitian yang digunakan adalah melakukan rancangan blade cengkirik, tinggi ideal cengkirik ketika di posisikan sebagai penangkap angin pada median jalan raya, kemudian dilakukan pemilihan generator yang sesuai dengan kecepatan angin yang tersedia. Pembangkit Listrik Tenaga Angin mengkonversikan energi angin menjadi energi listrik dengan menggunakan turbin angin bentuk cengkirik di dapat kecepatan angin akibat pergerakan kendaraan yang di ukur di median jalan antara $1,5 \mathrm{~m} / \mathrm{s}$ s/d $5,7 \mathrm{~m} / \mathrm{s}$. Dengan luas penampang turbin $0.9 \mathrm{~m}^{3}$ di dapat hasil pengujian 3 nilai tertinggi sebesar 6,36 Watt dengan kecepatan angin 4,25 m/s, 7,24 Watt dengan kecepatan angin 4,30 m/s dan 6,32Watt dengan kecepatan angin 4,13 m/s. Hal ini dapat menjelaskan bahwa energi angin dari arus jalan raya, Jalan tol lingkar utara dan jalan tol lingkar selatan juga dapat dimanfaatkan sebagai sumber listrik walau kecepatan angin tidak menentu.
\end{abstract}

Kata kunci : Baling-baling, tenaga listrik, penerangan jalan

\begin{abstract}
One of the developed power plants is to innovate through the shape and type of propellers. This wind power plant uses traditional propellers called cengkirik Basically, this wind turbine made of cengkirik is designed to capture the energy from low speed wind which is then forwarded to the rotating rotors due to the push from the wind due to the speed of the vehicle. This research was conducted using theoretical and experimental approaches. against wind turbines. The research method used is to do the design of the cengkirik blade, the ideal height of cengkirik when positioned as a wind catcher on the median of the highway, then the selection of generators is done according to the available wind speed. Wind Power Plant converts wind energy into electrical energy by using a good-looking wind turbine to obtain wind speed due to the movement of the vehicle measured in the median path between $1.5 \mathrm{~m} / \mathrm{s}$ to $5.7 \mathrm{~m} / \mathrm{s}$. With a cross section of $0.9 \mathrm{~m} 3$ turbine, the highest 3 values of the test are 6.36 Watts with wind speeds of $4.25 \mathrm{~m} / \mathrm{s}, 7.24$ Watt with wind speeds of $4.30 \mathrm{~m} / \mathrm{s}$ and $6.32 \mathrm{Watt}$ with 4 wind speeds, $13 \mathrm{~m} / \mathrm{s}$. This can explain that wind energy from highway flows,
\end{abstract}


northern ring toll road and southern ring toll road can also be used as a source of electricity even though the wind speed is uncertain.

Keywords: Propellers, electric power, street lighting.

\section{PENDAHULUAN}

Kebutuhan energi listrik sekarang iini sudah bisa dikatakan menjadi kebutuhan primer bagi setiap orang. Suply energi listrik yang ada sekarang ini sebagian besar berasal dari energi fossil yang lambat laun pasti akan musnah. Ketersediaan energi listrik sudah barang tentu menjadi tanggung jawab kita bersama. Sering kali dengan alasan penghematan energi listrik banyak jalan jalan utama di kota Banjarmasin menjadi kurang terang pada malam hari akibat kurangnya supply energi untuk jalan di maksud. Di dasari atas kebutuhan energi listrik yang dibutuhkan dalam setiap ruas jalan yang ada di kota Banjarmasin khususnya, maka penulis berinisiatif untuk menrancang instalasi yang bisa di manfaaatkan sebagai sumber tenaga listrik yang dapat digunakan di ruas jalan sebagai pengganti energi listrik ketika terjadi pemadamn listrik dari PLN maupun sebagai sumber energi utama. Alat ini berupa sebuah balingbaling (cengkirik) yang di rakit sedemikian rupa agar bisa mensupply energi listrik tersebut ketika balingbaling tersebut berputar akibat di tiup angin yang berasal dari hembusan kecepatan kendaraaan. Kemudian dengan bantuan generator akan dapat merubah energi listrik dan bisa di simpan dalam sebuah batery.

\section{TINJAUAN PUSTAKA}

Turbin angin atau dalam bahasa sederhana kincir angin merupakan turbin yang digerakkan oleh angin, yaitu udara yang bergerak diatas permukaan bumi. Sudah sejak dahulu angin berjasa bagi kehidupan manusia, salah satunya adalah para nelayan.
Selain itu, turbin angin pada awalnya juga dibuat untuk mengakomodasi kebutuhan para petani dalam melakukan penggilingan padi, keperluan irigasi, memompa air dan menggiling jagung. Penggunaan turbin angin terus mengalami perkembangan guna memanfaatkan energi angin secara efektif, terutama pada daerah - daerah dengan aliran angin yang relatif tinggi sepanjang tahun.

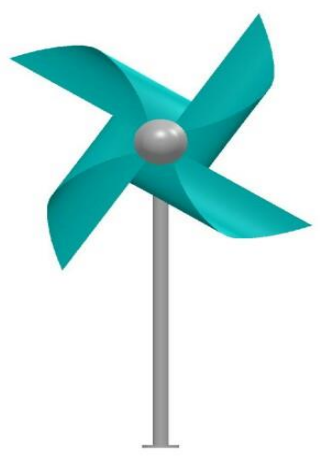

Gambar 1, Bentuk kincir (Cengkirik)

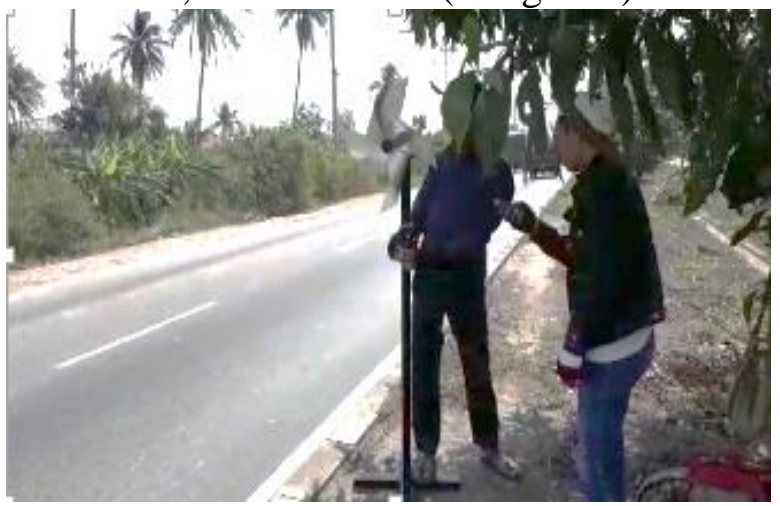

Gambar 2. Proses Pengambilan Data

\begin{tabular}{|c|c|c|}
\hline \multicolumn{3}{|c|}{$\begin{array}{c}\text { Tingkat Kecepatan Angin } 10 \text { meter } \\
\text { diatas Permukaan Tanah }\end{array}$} \\
\hline \begin{tabular}{l|l} 
Kelas \\
Angin
\end{tabular} & $\begin{array}{l}\text { Kecepetan } \\
\text { Angin } \mathbf{m} / \mathbf{s}\end{array}$ & $\begin{array}{c}\text { Kondisi Alam } \\
\text { didaratan }\end{array}$ \\
\hline 1 & $0.0 \sim 0.2$ & \\
\hline
\end{tabular}




\begin{tabular}{|c|c|c|}
\hline 2 & $0,3 \sim 1,5$ & $\begin{array}{l}\text { Angin tenang asap } \\
\text { lurus ke atas }\end{array}$ \\
\hline 3 & $1,6 \sim 3,3$ & $\begin{array}{l}\text { Asap bergerak } \\
\text { mengikuti arah angin }\end{array}$ \\
\hline 4 & $3,4 \sim 5,4$ & $\begin{array}{l}\text { Wajah terasa ada } \\
\text { angin, daun-daun } \\
\text { bergoyang pelan, } \\
\text { penunjuk arah angin } \\
\text { bergerak }\end{array}$ \\
\hline 5 & $5,5 \sim 7,9$ & $\begin{array}{l}\text { Debu jalan, kertas } \\
\text { berterbangan, ranting } \\
\text { pohon bergoyang. }\end{array}$ \\
\hline 6 & $8,0 \sim 10,7$ & $\begin{array}{l}\text { Ranting pohon } \\
\text { bergoyang, Bendera } \\
\text { berkibar }\end{array}$ \\
\hline 7 & $10,8 \sim 13,8$ & $\begin{array}{l}\text { Ranting pohon besar } \\
\text { bergoyang, Air } \\
\text { plumpang berombak } \\
\text { kecil. }\end{array}$ \\
\hline 8 & $13,9 \sim 17,1$ & $\begin{array}{l}\text { Ujung pohon } \\
\text { melengkung, } \\
\text { Hembusan Angin } \\
\text { terasa ditelinga }\end{array}$ \\
\hline 9 & $17,2 \sim 20,7$ & $\begin{array}{l}\text { Dapat mematahkan } \\
\text { ranting pohon, jalan } \\
\text { berat melawan arah } \\
\text { angin. }\end{array}$ \\
\hline 10 & $20,8 \sim 24,4$ & $\begin{array}{l}\text { Dapat mematahkan } \\
\text { ranting pohon, Rumah } \\
\text { roboh. }\end{array}$ \\
\hline 11 & $24,5 \sim 28,4$ & $\begin{array}{l}\text { Dapat merubuhkan } \\
\text { pohon, Menimbulkan } \\
\text { kerusakan. }\end{array}$ \\
\hline 12 & $28,5 \sim 32,6$ & $\begin{array}{l}\text { Menimbulkan } \\
\text { kerusakan parah. }\end{array}$ \\
\hline 13 & $32,7 \sim 36,9$ & Tornado \\
\hline
\end{tabular}

Definisi dari density adalah massa dari suatu fluida dalam satu satuan volume, atau $\mathrm{p}=\mathrm{m} / \mathrm{v}$, lain, yaitu $T$ (temperature) dan $S$ (salinity: untuk kasus air laut). Kenaikan $\mathrm{T}$ memberikan kontribusi penurunan kerapatan pada sebuah boundary sistem yang seragam. Kerapatan udara kering yang diambil sebagai konstanta pada perhitungan daya keluaran sebuah pembangkit listrik tenaga angin adalah $1,225 \mathrm{~kg} / \mathrm{m}^{3}$. Pada tabel Thermophysical property kita dapatkan bahwa nilai density udara tersebut terjadi pada kondisi temperatur sekitar $15{ }^{\circ} \mathrm{C}$.

Berdasarkan property physical udara seharusnya nilai $\mathrm{p}=1,225 \mathrm{~kg} / \mathrm{m} 3$ kurang tepat jika digunakan untuk wilayah Indonesia, karena temperatur yang berkorelasi seharusnya sekitar 15 ${ }^{\circ} \mathrm{C}$. Hal ini tidak mungkin didapati di wilayah pesisir dan pantai pada siang hari, mengingat temperatur ambient $\begin{array}{llll}\text { sekitar } & 28 & { }^{\circ} \mathrm{C}-32 & { }^{\circ} \mathrm{C}\end{array}$ $\left(1,15741<\mathrm{p}<1,1726 \mathrm{Kg} / \mathrm{m}^{3}\right)$. Demikian pula untuk data pada malam hari, dengan turunnya temperatur maka seharusnya terjadi kenaikan kerapatan.

Satu Small Wind Turbine dapat menghasilkan 1 kilowatt atau setara dengan $1000 \mathrm{~W}$ dengan minimal kecepatan angin rata-rata sebesar $3 \mathrm{~m} / \mathrm{s}$. Sedangkan untuk turbin angin berskala besar $(100 \mathrm{~kW})$ dapat digerakkan dengan kecepatan angin rata-rata $5 \mathrm{~m} / \mathrm{s}$. Nilai ekonomis Small Wind Turbine minimal 15 tahun.

Untuk mendesain sebuah turbin angin ada banyak hal yang harus diperhatikan, hal pertama yang harus dipertimbangkan yaitu berapa besar daya yang kita butuhkan, kecepatan angin, diameter rotor, setelah itu yang tidak kalah penting yaitu berapa jumlah sudu (blade) yang harus digunakan, dan masih banyak hal teknis lainnya. Oleh karena itu, kincir atau turbin angin sering disebut sebagai Sistem Konversi Energi Angin (SKEA). Dengan demikian maka energi yang dapat dihasilkan per satuan waktu adalah sesuai dengan rumus:

$$
\begin{aligned}
\text { Pangin } & =\text { Energi / waktu } \\
& =\left(1 / 2 \cdot \mathrm{m} \cdot \mathrm{v}^{2}\right) / \mathrm{t} \\
& =1 / 2 \cdot \mathrm{m} / \mathrm{t} \cdot \mathrm{v}^{2} \\
& =1 / 2 \cdot m \cdot \mathrm{v}^{2} \\
& =1 / 2 \cdot \mathrm{Cp} \cdot \rho \cdot \mathrm{A} \cdot \mathrm{v}^{3}
\end{aligned}
$$

Kalo di masukan hasil pengukuran di atas maka di dapat $\mathrm{P}$ angin 


$$
\begin{aligned}
& \mathrm{P} \text { angin }=1 / 2 \text {. Cp. . . A . v3 } \\
& 5.7 \mathrm{~m} / \mathrm{s} \\
& =1 / 2 \cdot \times 1.005 \mathrm{~kJ} /\left(\mathrm{kg}^{\circ} \mathrm{C}\right) \times 1.2 \mathrm{~kg} / \mathrm{m} 3 \times .0 .9 \mathrm{~m} 2 \times \\
& =3,0933 \text { Watt } / \text { detik }
\end{aligned}
$$

Di mana :

$$
\begin{aligned}
& \mathrm{P}=\text { daya angin } \\
& \mathrm{E}=\text { energi angin } \\
& \mathrm{t}=\text { waktu }
\end{aligned}
$$

Untuk mendesain turbin angin perlu diperhatikan tentang, bentuk dan jumlah sudu yang digunakan, bentuk dari sudu itu juga tergantung dari karakteristik angin di suatu tempat, ketika sudah diketahui karakteristik angin ini baru kemudian dapat ditentukan bentuk sudu mana yang akan dipakai (Hugh Piggott : 1997). Jumlah sudu (Blade) dapat dicari menggunakan persamaan berikut :

$$
B=\frac{80}{\lambda^{2}}
$$

Di mana :

$B=$ Jumlah sudu

$\lambda=$ Tip speed ratio

Tip Speed Ratio $(\lambda)$ merupakan perbandingan antara kecepatan putar turbin terhadap kecepatan angin, TSR dilambangkan dengan $\lambda$. Mittal, (2001). Untuk menghitung Tip Speed Ratio dapat menggunakan persamaan berikut :

Di mana :

$$
\lambda=\frac{\omega \cdot R}{v_{w}}
$$

$\lambda=$ tip speed ratio

$\omega=$ kecepatan sudut turbin $\quad(\mathrm{rad} / \mathrm{s})$

$\mathrm{R}=$ jari-jari turbin $\quad$ (m)

$\mathrm{V}_{\mathrm{w}}=$ kecepatan angin $(\mathrm{m} / \mathrm{s})$

Sebaliknya kecepatan putar poros dapat dihitung menggunakan persamaan berikut:

$$
S S=\frac{60 \cdot v \cdot \lambda}{\pi \cdot D}
$$

Di mana:

$$
\begin{aligned}
& S S=\text { Kecepatan Poros (rpm) } \\
& \lambda=\text { Kecepatan ujung bilah/Tip speed } \\
& \quad \text { ratio }
\end{aligned}
$$

Sehingga Break horse power atau daya dari turbin yang diukur setelah mengalami pembebanan yang disebabkan oleh generator, gearbox, pompa ataupun perangkat tambahan lainnya. Break yang dmaksud adalah suatu peralatan yang digunakan untuk memberikan beban pada turbin. Dalam percobaan nantinya $B H P$ diukur menggunakan motor listrik. Dengan mengukur tegangan yang dihasilkan dapat mengetahui besarnya daya generator, seperti pada rumus :

$$
P_{\text {generator }}=V \times I \text {. }
$$

Di mana :

$P_{\text {generator }}=$ Daya motor listrik $\quad(\mathrm{W})$

$V \quad=$ Tegangan motor listrik (Volt)

$I=$ Arus listrik

(Ampere)

Besarnya $B H P$ dapat dihitung setelah didapat harga $P_{\text {generator }}$ dengan rumus sebagai berikut :

Di mana :

$$
B H P=\frac{P_{\text {generator }}}{n_{\text {generator }}}
$$

$\mathrm{BHP}=$ Break horse power (W) $P_{\text {generator }}=$ Daya motor listrik $0,02(\mathrm{~W})$ $\eta_{\text {generator }}=$ Efesiensi generator $85(\%)$

$$
\begin{aligned}
& B H P=\frac{P_{\text {generator }}}{n_{\text {generator }}} \\
& B H P=\frac{0,020}{0,85} \\
& B H P=23 \%
\end{aligned}
$$

\section{HASIL DAN PEMBAHASAN}

Nilai Rata-rata Pengujian Arus Dan Tegangan Kincir Angin

Tipe Cengkirik 4 Sudu Selama 7 Hari Di Dalam Kota

\begin{tabular}{|c|c|c|c|c|}
\hline \multirow{2}{*}{ Hari } & \multirow{2}{*}{$(\mathbf{m} / \mathbf{s})$} & \multicolumn{3}{|c|}{ Daya generator } \\
\cline { 3 - 5 } & & $\mathbf{I}$ & $\mathbf{V}$ & Watt \\
\hline ke 1 & 1,60 & 0,21 & 0,30 & 0,063 \\
\hline
\end{tabular}




\begin{tabular}{|l|l|l|l|l|} 
ke 2 & 2,00 & 1,01 & 1,20 & 1,21 \\
\hline ke 3 & 2,50 & 1,19 & 1,30 & 1,54 \\
\hline ke 4 & $\mathbf{4 , 0 1}$ & $\mathbf{3 , 1 9}$ & $\mathbf{2 , 2 3}$ & $\mathbf{7 , 1 1}$ \\
\hline ke 5 & 3,30 & 2,08 & 2,02 & 4,1 \\
\hline ke 6 & $\mathbf{3 , 6 0}$ & $\mathbf{2 , 2 7}$ & $\mathbf{2 , 0 6}$ & $\mathbf{4 , 6 7}$ \\
\hline ke 7 & $\mathbf{3 , 7 4}$ & $\mathbf{2 , 3 7}$ & $\mathbf{2 , 1 8}$ & $\mathbf{5 , 1 6}$ \\
\hline
\end{tabular}

Tabel 4.1 Nilai Rata-rata Pengujian Arus Dan Tegangan Kincir Angin Tipe Cengkirik 4 Sudu Selama 7 Hari Di Jalan Tol Lingkar Utara

\begin{tabular}{|c|c|c|c|c|}
\hline \multirow{2}{*}{ Hari } & \multirow{2}{*}{$\mathrm{v}(\mathrm{m} / \mathrm{s})$} & \multicolumn{3}{|c|}{ Daya generator } \\
\cline { 3 - 5 } & & Ampere & Volt & Watt \\
\hline ke 1 & 1,91 & 0,25 & 0,35 & 0,087 \\
\hline ke 2 & 2,60 & 1,23 & 1,35 & 1,66 \\
\hline ke 3 & 1,20 & 0,06 & 0,35 & 0,021 \\
\hline ke 4 & 3,75 & 2,25 & 2,53 & 5,69 \\
\hline ke 5 & 3,84 & 2,3 & 2,71 & 6,23 \\
\hline ke 6 & $\mathbf{4 , 1}$ & $\mathbf{3 , 1 0}$ & $\mathbf{2 , 1 5}$ & $\mathbf{6 , 6 6}$ \\
\hline ke 7 & 1,76 & 0,08 & 0,81 & 0,064 \\
\hline
\end{tabular}

Tabel 4.2 Nilai Rata-rata Pengujian Arus Dan Tegangan Kincir Angin Tipe Cengkirik 4 Sudu Selama 7 Hari Di Jalan Tol Lingkar Selatan

\begin{tabular}{|c|c|c|c|c|}
\hline \multirow{2}{*}{ Hari } & \multirow{2}{*}{$\mathrm{v}(\mathrm{m} / \mathrm{s})$} & \multicolumn{3}{|c|}{ Daya generator } \\
\cline { 3 - 5 } & & Ampere & Volt & Watt \\
\hline ke 1 & 3,33 & 2,10 & 2,05 & 4,30 \\
\hline ke 2 & 2,19 & 1,03 & 1,28 & 1,31 \\
\hline ke 3 & 4,25 & 3,15 & 2,02 & 6,36 \\
\hline ke 4 & 4,30 & 3,45 & 2,10 & 7,24 \\
\hline ke 5 & 4,13 & 3,01 & 2,1 & 6,32 \\
\hline ke 6 & 1,12 & 0,4 & 0,21 & 0,084 \\
\hline ke 7 & 3,10 & 2,02 & 2,39 & 4,82 \\
\hline
\end{tabular}

\section{KESIMPULAN}

Berdasarkan penelitian yang telah dilakukan diperoleh kesimpulan dalam perancangan dan pembuatan turbin angin sumbu horizontal model cengkirik dengan jumlah 4 sudu diperoleh kesimpulan data yang tertinggi sebagai berikut :

1. Tiga hasil penelitian yang tertinggi di dalam kota yaitu ;

1) $4,01 \mathrm{~m} / \mathrm{s}$ menghasilkan listrik 7,11 Watt dengan suplay daya generator 2,23 Volt.

2) $3,74 \mathrm{~m} / \mathrm{s}$ menghasilkan listrik 5,16 Watt dengan suplay daya generator 2,18 Volt.

3) $3,60 \mathrm{~m} / \mathrm{s}$ menghasilkan listrik 4,67 Watt dengan suplay daya generator 2,06 Volt.

2. Hasil penelitian dilakukan di jalan tol lingkar utara yaitu :

1) $4,0 \mathrm{~m} / \mathrm{s}$ menghasilkan listrik 6,66 Watt dengan suplay daya generator 2,15 Volt.

2) $3,84 \mathrm{~m} / \mathrm{s}$ menghasilkan listrik 6,23 Watt dengan suplay daya generator 2,71 Volt.

3) $3,75 \mathrm{~m} / \mathrm{s}$ menghasilkan listrik 5,69 Watt dengan suplay daya generator 2,53 Volt.

3. Hasil penelitian dilakukan di jalan tol lingkar selatan yaitu

1) $3,45 \mathrm{~m} / \mathrm{s}$ menghasilkan listrik 7,24 Watt dengan suplay daya generator 2,10 Volt.

2) $3,15 \mathrm{~m} / \mathrm{s}$ menghasilkan listrik 6,36 Watt dengan suplay daya generator 2,02 Volt.

3) $3,01 \mathrm{~m} / \mathrm{s}$ menghasilkan listrik 6,32 Watt dengan suplay daya generator 2,1 Volt.

\section{SARAN}

Rancangan turbin angin sumbu horizontal model cengkirik dengan 4 sudu sederhana ini sudah sebagian besar memenuhi atribut dari pelanggan, tetapi ada kemungkinan yang dapat dilakukan pada penelitian berikutnya. Saran untuk peneliti berikutnya adalah :

1. Memperbaiki performasi putaran sudu yang lebih ringgan.

2. Rancangan turbin angin ini dapat dioptimalkan dengan pemilihan generator, accumulator, hingga output ke alat elektronik yang tepat 
agar output menjadi lebih optimal lagi.

3. Rangka penyangga diperkuat agar alat lebih kokoh saat angin besar datang dan dapat disesuaikan dengan penempatannya.

\section{REFERENSI}

[1] Ahmad Sayogo, Novi Caroko, S.T., M.Eng, Wahyudi, S.T., M.T. Perancangan Dan Pembuatan Kincir Angin Tipe Horizontal Axis Wind Turbine (Hawt) Untuk Daerah Pantai Selatan Jawa.

[2] Budhi Prasetiyo, (2015), Turbin Angin Sumbu Horizontal Tipe TSD 500 Pada Beban Konstan.

[3] Firman Haryanto, (2013). Turbin angin adalah alat yang mengubah energi angin menjadi energi mekanik dan kemudian diubah menjadi energi listrik melalui generator.

[4] Ibnu Khamdan Almasuun, (2016). Perancangan Turbin Angin Sumbu Horizontal 1500 Watt Di Pantai Wisata Suwuk Kabupaten Kebumen.

[5] Maret Eggar Prasetya, (2015). Studi Kinerja Turbin Angin Sumbu Horizontal NACA 4412 dengan Modifikasi Sudu Tipe Flat Pada Variasi Sudut Kemiringan $0^{\circ}, 10^{\circ}$, $15^{\circ}$.

[6] Royan Romadhon, (2017), Perancangan Turbin Angin Sumbu Horisontal 1000 Watt di Pelabuhan Karimun Jawa Kabupaten Jepara.

[7] Weldy Yudiansyah, Ibnu Kahfi Bachtiar, Eko Prayetno, (2018), Perancangan Turbin Angin MultiBlade Poros Horizontal Tipe American Multi-Blade. 